\section{OxDONS syndrome}

\section{Message of article is still valid}

EDITOR,-Civil servants are wont to interpret the rules to suit their own ends, and I wonder if Colin Reeves succumbed to this temptation in his commentary on my article. ${ }^{1}$ Although he states that trusts can accumulate a surplus from income from private patients, he does not state whether this surplus can be transferred from one financial year to the next. If the rules prevent such transfer (which means that the surplus has to be spent in the current year) then clearly it is going to be difficult, if not impossible, to expand the facilities to any extent. Does such a rule exist for income from private patients? If it does, it ought to be abolished.

Since I described the OxDONS syndrome, Radcliffe Infirmary's administration has, at last, recognised the error of one of its ways: it now calculates the neurosurgical cost to NHS patients (and hence prices to purchasers) by excluding any surplus from private patients in the calculation. This is tacit acceptance of Reeves's statement that trusts can do this. Why didn't they do it before?

Reeves's assertion that resources follow patients will fool nobody. All consultants know that they are seeing more patients for fewer resources, especially when it comes to block contracts. I suppose that, as an economical civil servant, Reeves would say that resources still follow patients, even if those resources become fewer per patient each year.

The message of the OxDONS syndrome is still valid. If clinicians bring in private patients to NHS hospitals and if income from these patients is used as revenue, not capital, then they will be financially destroying their own departments. You have been warned.

C B T ADAMS

23 Banbury Road

Oxford OZ2 6NX

1 Adams CBT. OxDONS syndrome: the inevitable disease of the NHS reforms. BMF 1995;311:1559-61. [With commentary by C Reeves.] ( 9 December.)

\section{Oxford case may be start of epidemic}

EDITOR,-I was fascinated to read C B T Adams's report on a new disease, the OxDONS syndrome. ${ }^{1}$ Colleagues and I have been attempting to treat an almost identical case for the past five years and believe that this may herald the onset of an epidemic. Both patients seem to have a lot in common: Oxford's department of neurological surgery has a reputation for excellent care of patients, as has our patient (Exeter's Princess Elizabeth Orthopaedic Hospital). Both the Oxford department and our hospital are subregional centres with a proud history. Both have a reputation for innovation and research, run higher surgical training schemes, and were extremely efficient at the time of the introduction of the health service reforms. Both were subregional centres obtaining resources from a local health authority that was not particularly interested in regional services.
Our hospital was ranked number one in terms of the number of orthopaedic and trauma operations performed in 1994-5 in the south west and in efficiency, having the shortest length of stay for both hip and knee replacement. The surgeons saw 4972 outpatients per consultant firm per year, compared with 1482 per consultant general surgical firm. Five senior house officers service 44 cold orthopaedic lists a week, compared with 16 surgical house officers and senior house officers servicing 36 cold general surgical lists. The hospital has just four registrars for a consultant staff of 15 consultant surgeons and two consultant rheumatologists. As with Adams's department, our hospital was hyperefficient and this is what led to its demise.

Also as with Adams's department, the financial rule that broke our hospital was that "prices have to follow costs." Altogether 4338 cold orthopaedic operations (and 2056 operations for fractures) were performed in 1994-5, leading to one of the lowest costs for joint replacement in the region. As clinical director I suggested that we must set our prices for 1995-6 at $£ 5$ less than the regional average. This, however, would have led to an income $f 1.1 \mathrm{~m}$ above our costs, which is not allowed under NHS accounting rules. Thus by working harder and more efficiently than our competitors we were essentially performing $£ 1.1 \mathrm{~m}$ worth of surgery free of charge, with an unsustainable workload which has led to a breakdown in morale and financial meltdown.

The saddest aspect of this newly discovered syndrome is Colin Reeves's dismissal of it. ${ }^{1}$ To dismiss Adams's eloquently argued article as Reeves does shows a lack of insight inconsistent with Reeves's office as director of finance of the NHS Executive.

Princess Elizabeth Orthopaedic Hospital

Exeter EX2 4UE

1 Adams CBT. OxDONS syndrome: the inevitable disease of the NHS. BMf 1995;311:1559-61. [With commentary by C Reeves.] (9 December.)

\section{Edinburgh's orthopaedic trauma unit has similar problems}

EDrroR,-C B T Adams's article detailing the problems of underresourcing that many units have experienced since the introduction of the NHS reforms will have struck a chord with many hospital doctors, particularly those working in trauma or emergency care. ${ }^{1}$ Most would now agree that money has not followed patients, but the reality is that the flow of money has continued to be guided by political expediency. Adams concludes that in the end units such as his will be providing only an emergency service, and he may well be correct in this assumption. We wish to draw attention to the current problems of running an orthopaedic trauma unit.

The orthopaedic trauma unit in the Royal Infirmary of Edinburgh NHS Trust has been one of the world's most committed orthopaedic trauma units in recent years, publishing more original papers in the orthopaedic trauma literature than any other unit. Like the department of neurological surgery in the Radcliffe Infirmary, however, we were inadequately financed to start with and, despite increasing efficiency, find ourselves victims of the system. We now perform over $60 \%$ of the orthopaedic surgery in Edinburgh but have less than $20 \%$ of the consultant sessions. Our bed occupancy averages $110.5 \%$, and by NHS criteria we are 35 nurses short of an acceptable establishment. The consultants can now operate only on difficult fractures and complicated reconstructive procedures, and the inevitable effect is that over $80 \%$ of the surgery is unsupervised and done by surgeons in training. Obviously this leads to costly complications, which erode our progressively diminishing budget.

We doubt that we are alone. The inevitable effect of the NHS reforms has been to focus on elective problems, the distribution of resources having been driven by the problems of elective waiting lists. Patients with trauma have little political clout and consequently do not attract the interest of managers and politicians. We do not want to discourage Adams further, but without improved funding for emergency work the situation will undoubtedly deteriorate.

C M COURT-BROWN Consultant orthopaedic surgeon M M MCQUEEN

Consultant orthopaedic surgeon J CHRISTIE Consultant orthopaedic surgeon

Edinburgh Orthopaedic Trauma Unit,

Royal Infirmary of Edinburgh,

Edinburgh EH9 3YW

1 Adams CBT OxDONS syndrome: the inevitable disease of the NHS reforms. BMF 1995;311:1559-61. [With commentary by C Reeves.] (9 December.)

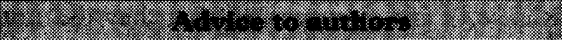

We receive more letters than we can publish: we can currently accept only about one third. We prefer short letters that relate to articles published within the past four weeks. Letters received after this deadline stand less chance of acceptance. We also publish some "out of the blue" letters, which usually relate to matters of public policy.

When deciding which letters to publish we favour originality, assertions supported by data or by citation, and a clear prose style. Wit, passion, and personal experience also have their place.

Letters should have fewer than 400 words and no more than five references (including one to the BMJ article to which they relate); references should be in the Vancouver style. We welcome pictures.

Letters should be typed and signed by each author, and each author's current appointment and address should be stated. We encourage you to declare any conflict of interest.

Please enclose a stamped addressed envelope if you would like to know whether your letter has been accepted or rejected.

Letters will be edited and may be shortened. 